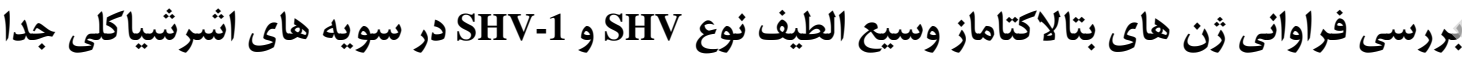

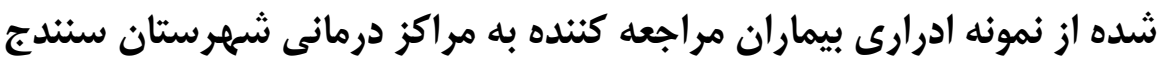

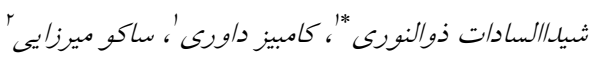

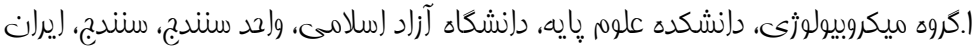

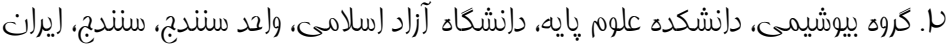

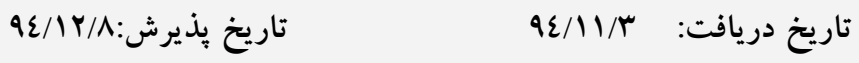

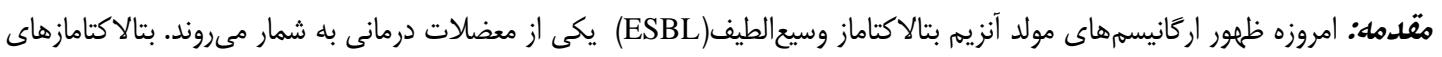

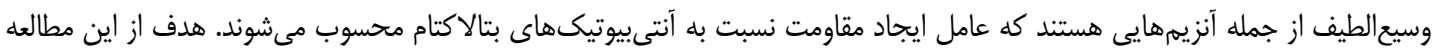

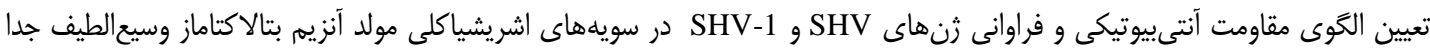

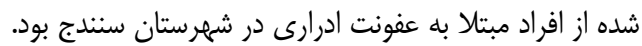

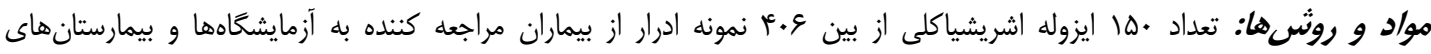

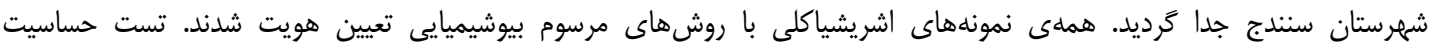

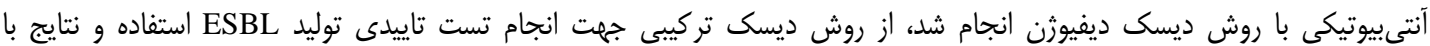

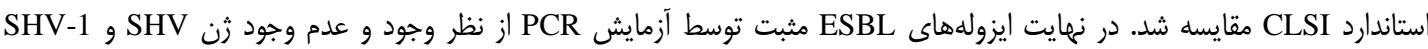
براسى شدند. يافتهاهى بثزوهثن: از تعداد •ها ايزولهى اشريشياكلى، مقاومت به آنتىبيوتيكهاى سفترياكسون، يِيبراسيلين، جنتامايسين، آميكاسين،

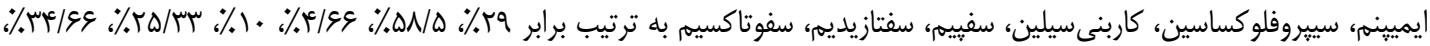

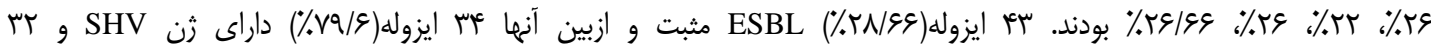

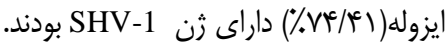
بحث و نتيجهَّيرى: با توجه به نتايج حاصل شده، فراوانى سويههاى مقاوم به آنتىبيوتيكها و همجنين سويههاى مولد ESBL در

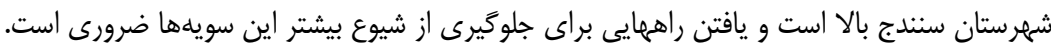

وازه هاى كليدى: اشريشياكلى، بتالاكتاماز وسيعالطيف، SHV-1،

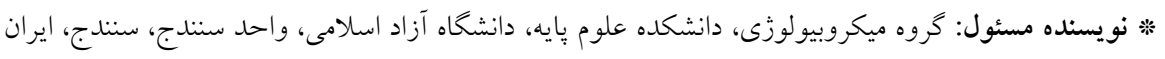

Email: Sheidazonoori@gmail.com

Copyright () 2017 Journal of Ilam University of Medical Science. This is an open-access article distributed under the terms of the Creative Commons Attribution international 4.0 International License (https://creativecommons.org/licenses/by-nc/4.0/) which permits copy and redistribute the material, in any medium or format, provided the original work is properly cited. 
عفونت ادرارى مىباشد و با توجه به اهميتى كه تعيين نوع و منشا زنتيكى زنهاى ايجاد كننده مقاومت دارد، فراوانى ثن SHV و اشريشياكلى مولد آنزيم بتالاكتاماز وسيع الطيف جدا شده نيز مورد بررسى قرار گرفت.

\section{مواد و روشها}

اين تحقيق توصيفى - مقطعى برروى بيماران مشكوى

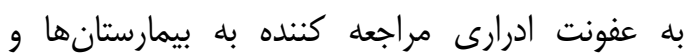
آزمايشگاههاى تشخيصى طبى شهرستان سنندج انجام

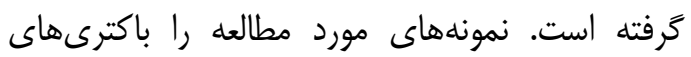
اشريشياكلى تشكيل مى داد و مجموعا 9.4 نمونه ادرار در فاصله زمانى آذر سو تا ارديبهشت عاد أد از افر اد مراجعه

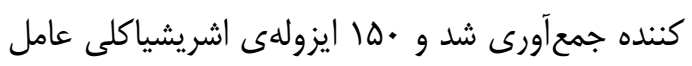

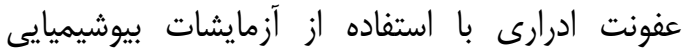

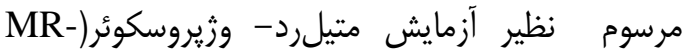

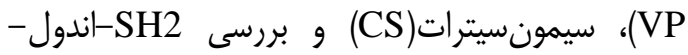

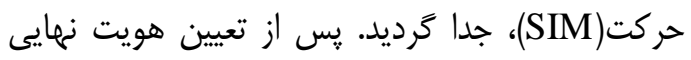

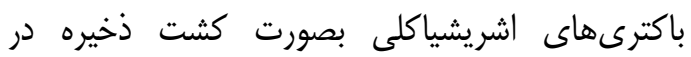

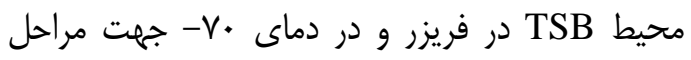

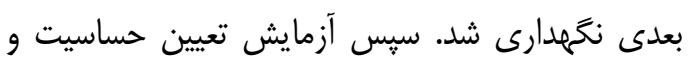

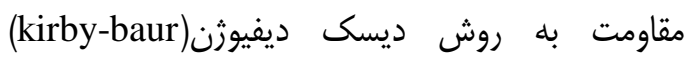

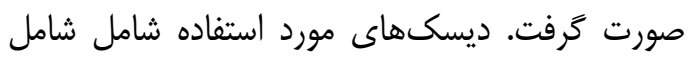
جنتامايسين(1) رو (l)،

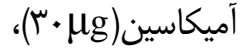

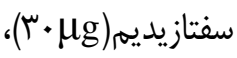

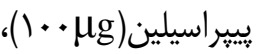

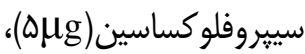

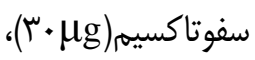

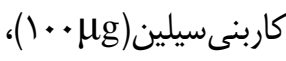

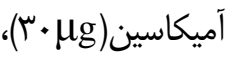

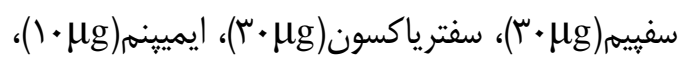
خريدارى شده از شركت Mast بودند.

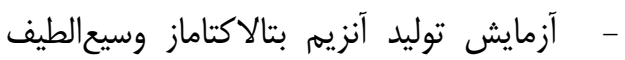

:(ESBL)

براى اين منظور از تست فنوتييى تاييدى( Phenotypic Confirmatory Test (ديسك تركيبى) استفاده شد. ديسكهاى مورد آزمايش شامل سفتازيديم/كلاولانيك اسيد)

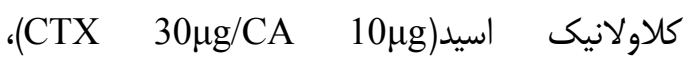
سفتازيديم و سفوتاكسيم از شركت Mast بودند. بعد از

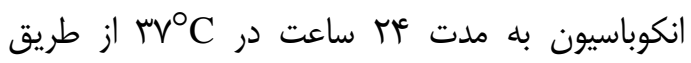

مقدمه:

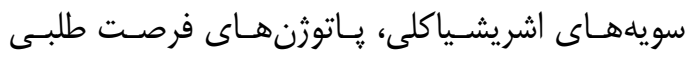

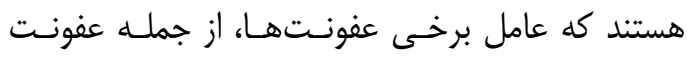

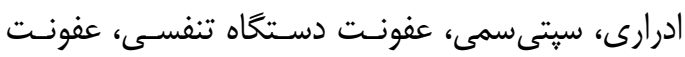

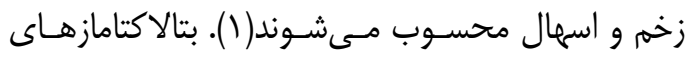

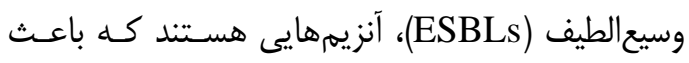

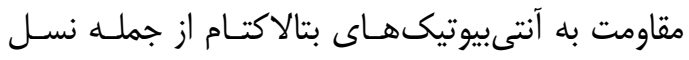
سوم سفالوسيورينها مانتـد سفوتاكسـيم، سـفتازيديم و سفترياكسون مىشوند(Y)، اين آنزيمها اغلب در خانواده

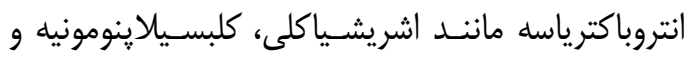

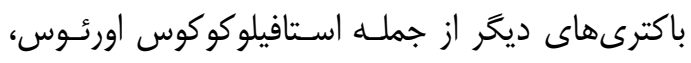

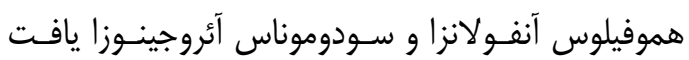

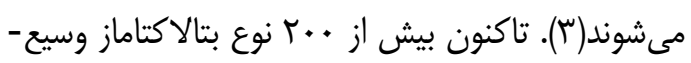

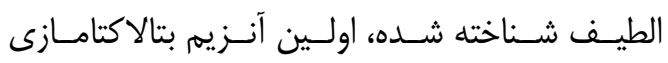

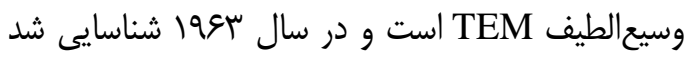

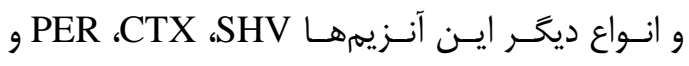

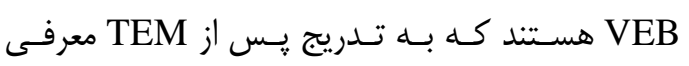

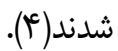
TEM-2 و TEM-1 SHV-1

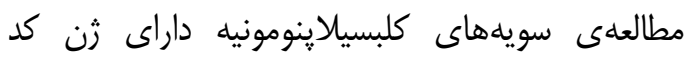

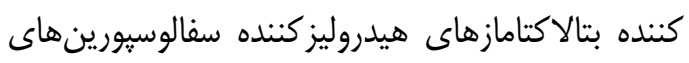

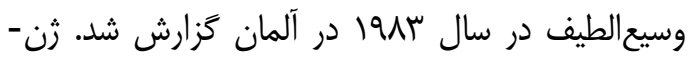

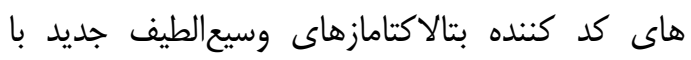

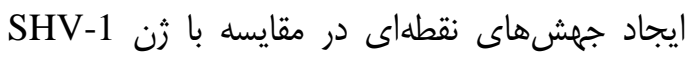
ايجاد شده است(ه). بدليل اينكه اين آنزيمها وابسته به به به

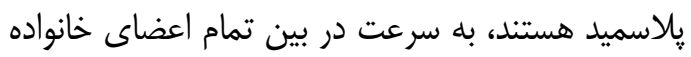

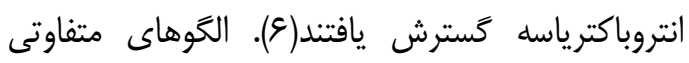
براى طبقهبندى بتالاكتامازهاى وجود دارد از جمله

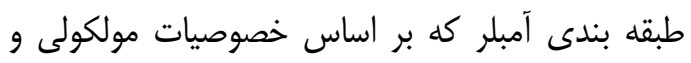

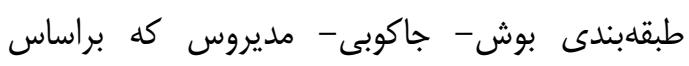

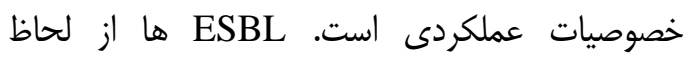
مولكولى در كلاس A و از لحاظ عملكردى در گروه ب

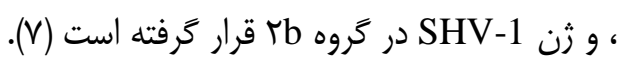

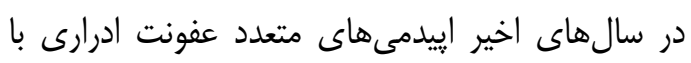

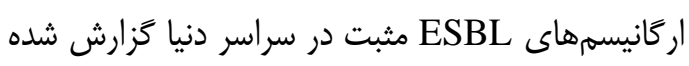
اند(^) هدف از اين مطالعه بررسى الخوى مقاومت و حساسيت آنتى بيوتيكى در آشريشياكلى هاى هالى عامل 
افزايش اختاف قطر هاله عدم رشد به اندازه هـ ميليمتر

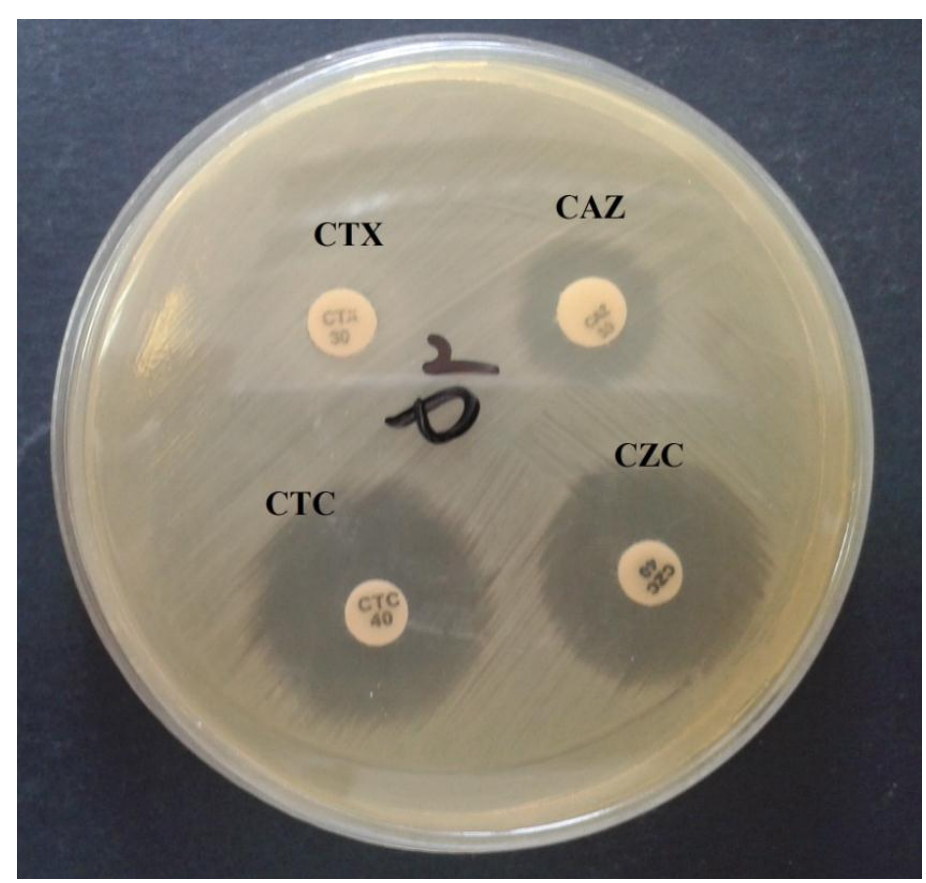

شكل (: نمونهاى از نتايج آزمايش ديسك تركيبى روى محيط مولرهينتون آكار

مخلوط واكنش در حجم نهايى roرl تهيه شد و تركيبات واكنش شامل الرا از هركدام از يرايمرهاى

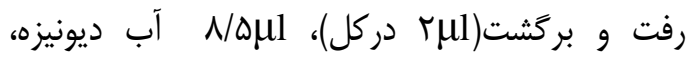

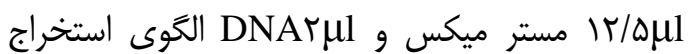
شده بود. مشخصات يرايمرهاى استفاده شده در جدول(1) ذكر شده است. و نتيجه آزمايش PCR با

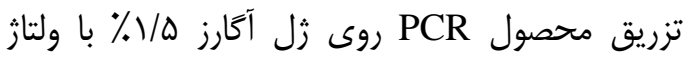

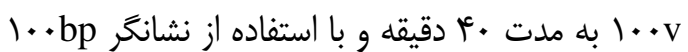
تعيين گر ديد.

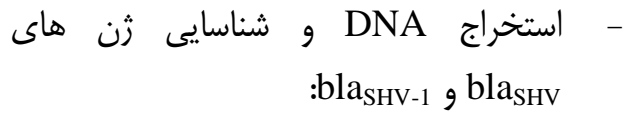

ايزوله هاى ESBL با استفاده از يروتكل قرار

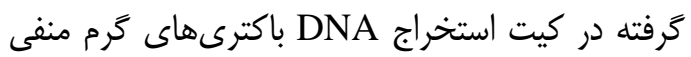
خريدارى شده از شركت سيناكلون استخراج شد، و والتحرئ

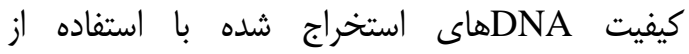
الكتروفورز زل آَارز مورد ارزيابى قرار كرفت.

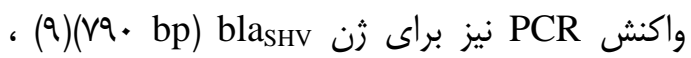

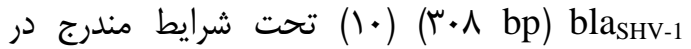

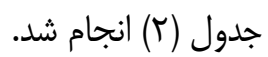

\begin{tabular}{|c|c|c|c|}
\hline نام يرايمر & توالى برايمر & اندازه قطعه تكثير شده(bp) & منبع \\
\hline SHV & $\begin{array}{l}\text { F:TTATCTCCCTGTTAGCCACC } \\
\text { R:GATTTGCTGATTTCGCTCGG }\end{array}$ & $\Lambda \cdot \Lambda$ & (9) \\
\hline SHV-1 & $\begin{array}{l}\text { F: CTGGGAAACGGAACTGAAT } \\
\text { R:GGGGTATCCCGCAGATAAAT }\end{array}$ & $r \cdot \Lambda$ & (1.) \\
\hline
\end{tabular}

جدول ا: توالى برايمرهاى استفاده شده 
شده اطراف ديسك هاى آنتى بيوتيك سفوتاكسيم و

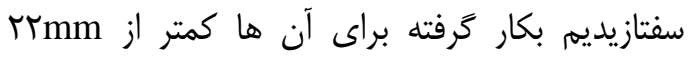

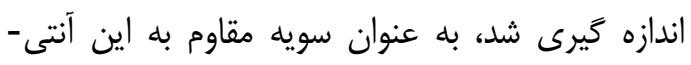

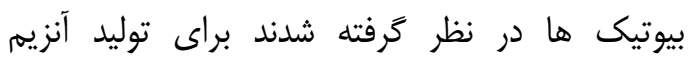

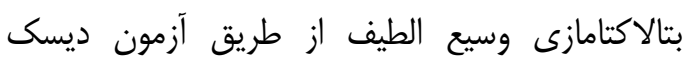

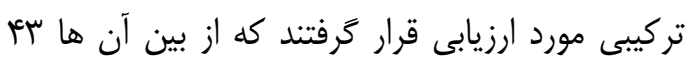

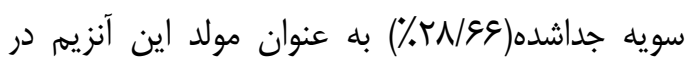
نظر گرفته شدند. در آزمايش PCR براى بررسى فراوانى ثن SHV و

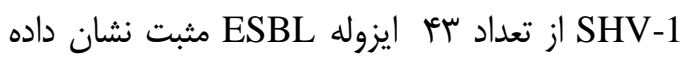

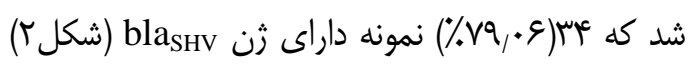
bla

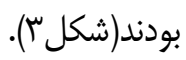

يافته هاى يزوهش

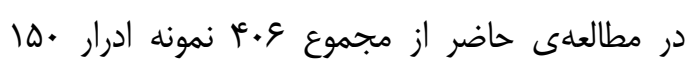

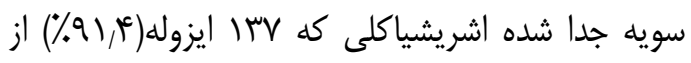

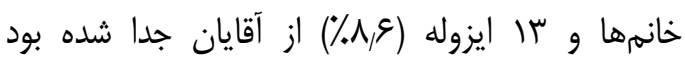

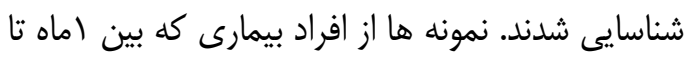

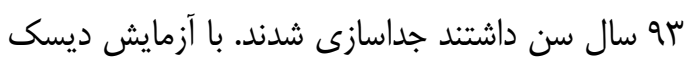

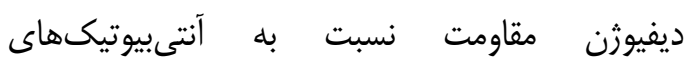

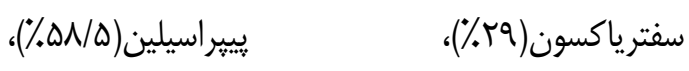

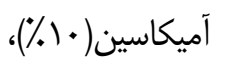

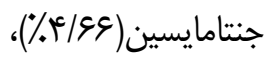

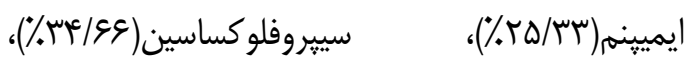

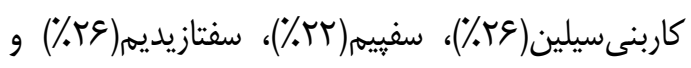

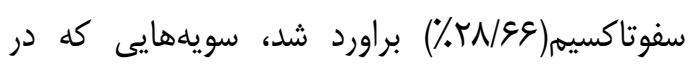
آزمايش ديسك ديفيوزن قطر هالدى عدم رشد ايجاد

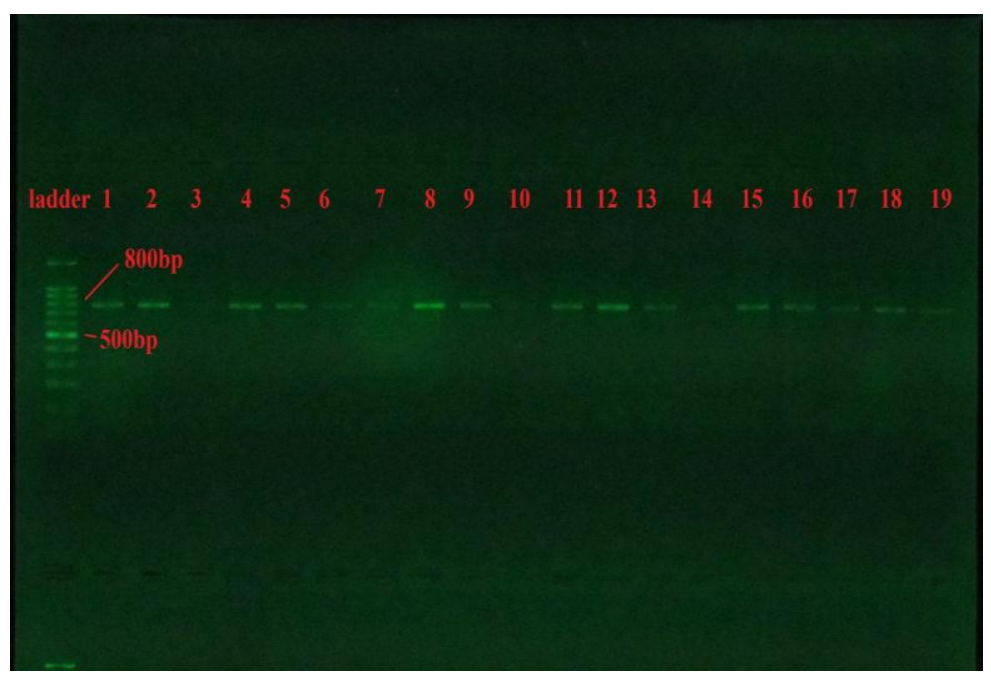

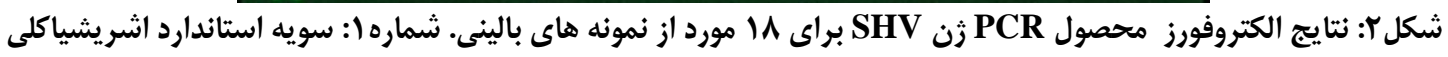

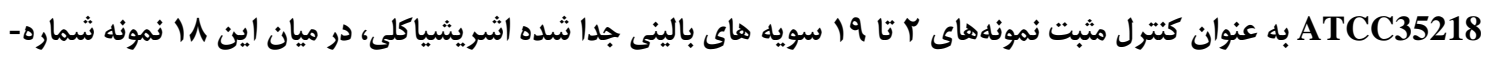

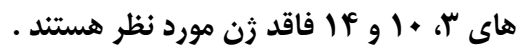

جهان محسوب مىشوند. اشريشياكلى مهم ترين عامل بحث و نتيجه كيرى عفونت هاى ادرارى اكتسابى از جامعه است، و ايزوله هاى توليد كننده ESBL اين باكترى در برابر بسيارى أرى إنس اشريشياكلى هاى مولد بتالاكتامازهاى وسيع الطيف (ESBL) 


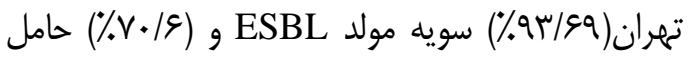
SHV ESBL عqسادر تهران نمونههاى اشريشياكلى بررسى شد كه

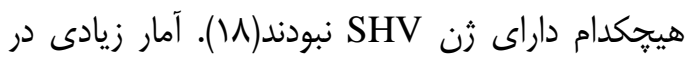

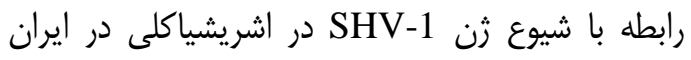

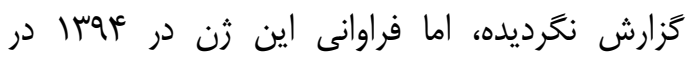

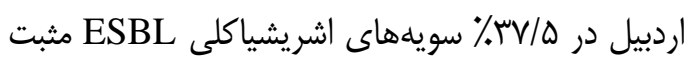
(\%) حاوى ثن SHV/V)

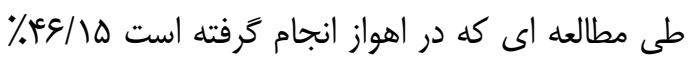

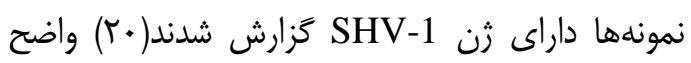

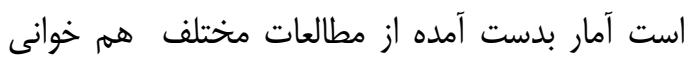

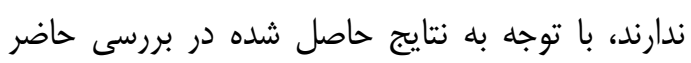

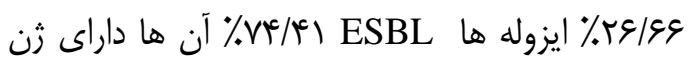
SHV-1

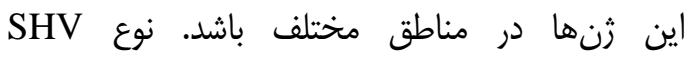

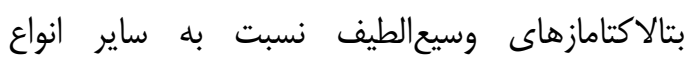
ESBL

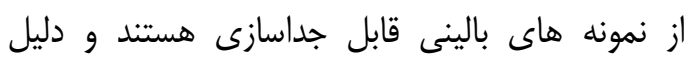
يراكندگى غير يكسان در مناطق جغرافيايى مىتواند به دليل يراكندگى مختلف جمعيت از لحاظ جنسيت و ونس افراد مراجعه كننده به مراكز درمانى در مقطع زمانى جنى إنى

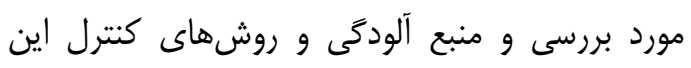

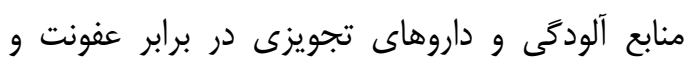
سطح بهداشت در مناطق مختلف جغرافيايى باشئ داشد. نتايج حاصل شده از اين بررسى نشان مىدهد، شيوع مناطئ

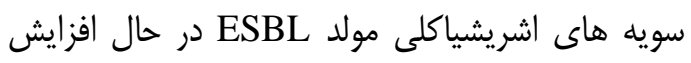
است و هم جنين فراوانى ثن بتالاكتامازى وسيع الطيف SHV-1 و SHV

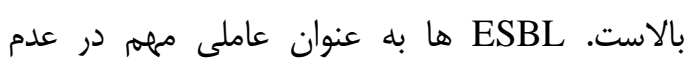

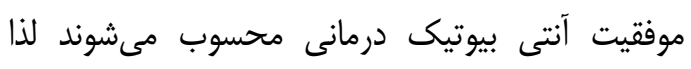
يافتن راه هايى براى جلوكيرى از شيوع بيشتر آن هان هاني

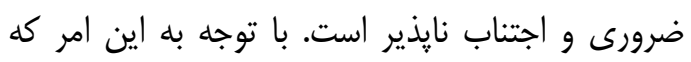
سويه هاى ESBL به فراوانى كسترش ييدا كردهاند

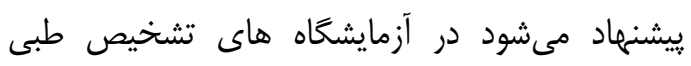

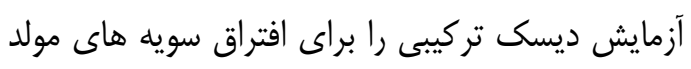

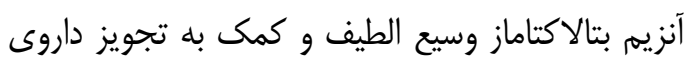

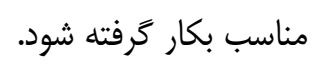

از عوامل ضد ميكروبى قابل استفاده براى درمان اين

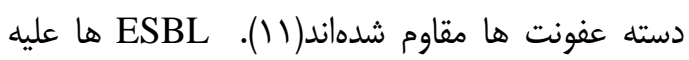

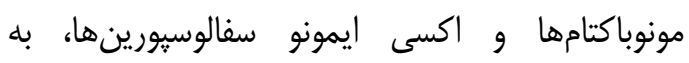
استثناى سفامايسين فعال هستند (ז)ا). در اين مطالعه

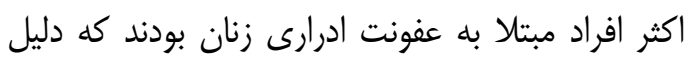

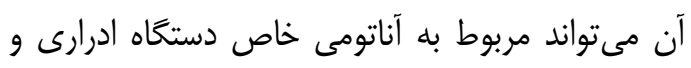

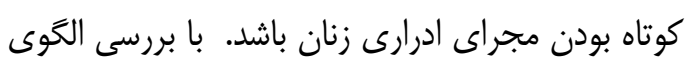

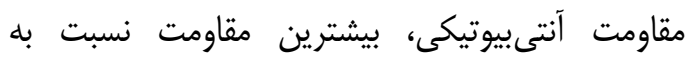

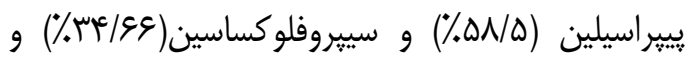

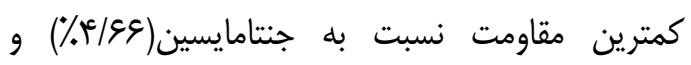

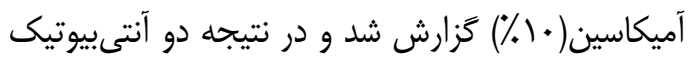

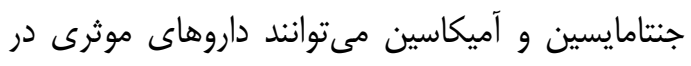
درمان عفونت ادرارى ناشى از اشريشياكلى باشند.

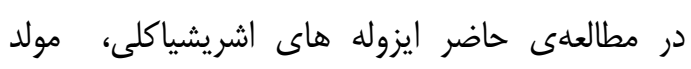

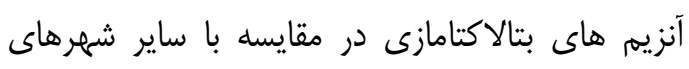

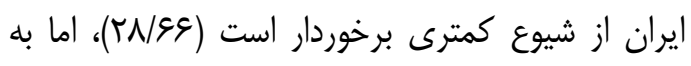

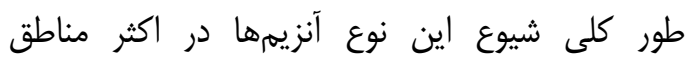

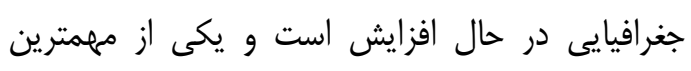

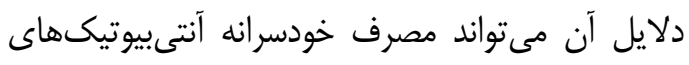

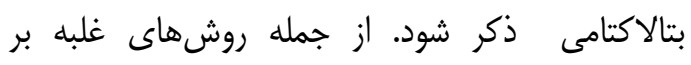

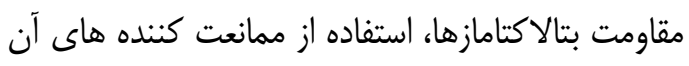

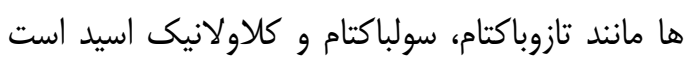
كه به صورت كووالانت به سايت فعال بتالاكتامازهاى كلاس A متصل مى شوند(س)

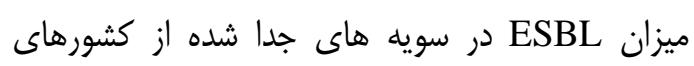
مختلف و هم هنين در يك كشور از يك بيمارستان با

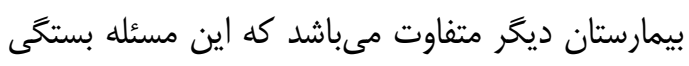

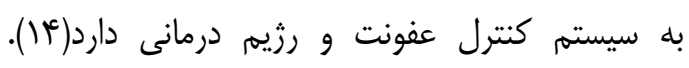
فراوانى ثن بتالاكتامازى نوع SHV و SHV-1

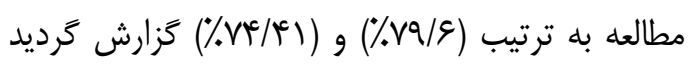

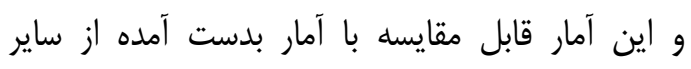

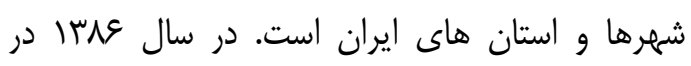
اصفهان فراوانى اشريشياكلى مولد ESBL

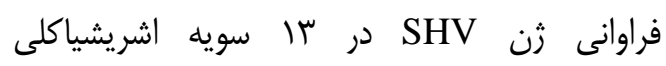

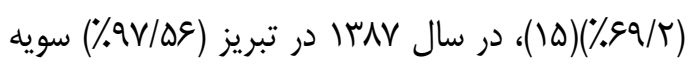

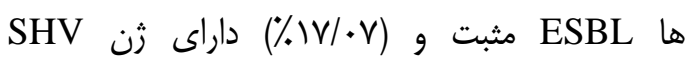

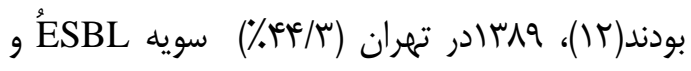

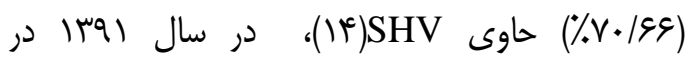




\section{References}

1.ALsubol I, Youssef N. Prevalence of CTX-M, TEM and SHV betalactamases in clinical isolates of Escherichia coli and Klebsiella pneumoniae isolated from Aleppo University hospitals Aleppo Syria. Arch Clin Infect Dis 2015; 10:211-9.

2.Ramazanzade R, Farhadifar F, Mansuri M. Etiology and antibiotic resistance patterns of community acquired extetnded spectrum betalactamase producing gram negative isolates in Sanandaj. Res J Med Sci 2010; 4:243-7.

3.Ashrafian F, Askari E, Kalamatizade E, Ghaboulishahroodi M, Naderinasab M. The frequency of extended spectrum beta lactamase in Escherichia coli and Klebsiella pneumoniae a report from Mashhad Iran. J Med Bacteriol 2013; 2:12-9.

4.Malloy AM, Campos JM. Extendedspectrum betalactamases a brief clinical update. Pediatr Infect Dis J 2011; 30:1092-3.

5.Chong Y. Extended-spectrum betalactamase producing bacteria an emerging clinical concern. Res Technol Adv2011;22:141-6.

6. Kurokawa H, Shibata N, Doi Y, Shibayama K. Kamachi N, Yagi T, et al. A new TEMderived extended-spectrum betalactamase with an R164C substitution at the $\Omega$-loop confers ceftazidime resistance. Antimicrob Agents Chemother 2013; 47:2981-3.

7.Sarah M, Bonomo D, Bonomo R. Three decades of b-lactamase inhibitors. Clin Microbiol Rev 2010; 23:160-201.

8.Haghighatpanah M, Amirmozafari N, Faezi M, Shenagar M. [The study of antibiotic resistance and detection of extended spectrum betalactamase in clinical isolates of ESBL producing Escherichia coli in Rasht]. J Ilam Uni Med Sci 2014;22:180-9. (Persian)

9.Sharma J, Sharma M, Ray P. Detection of TEM and SHV genes in Escherichia coli and Klebsiella pneumoniae isolates in a tertiary care hospital from India. Indian J Med Res 2010; 132:332-6.

10.Khosravi A, Hoveizavy H, Mehdinejad M. Prevalence of Klebsiella pneumoniae encoding genes for Ctx-M-1, Tem-1 and Shv-1 extended-spectrum beta lactamases enzymes in clinical specimens. Jundishapur J Microbiol 2012; 6:123-8.

11.Rodriguez J, Joan C, Joze M, Cisneros M, Grill F, Oliver A, etal. Community Infections Caused by Extended-Spectrum-Lactamase-producing Escherichia coli. Arch Int Med2008; 168:1897-902.

12.Mobasherkarjedi A, Nahai M, Mobin H, Pornur M, Sadeghi J. [Mulecular analyzis of beta extended-spectrun betalactamase gene type SHV in Eschrichia coli and Klebsiella pneumoniae isolates in clinical samples collected from 4 medical centre in Tabriz city]. Iran Med Microbiol J 2008; 2:9-17. (Persian)

13.Paganrodriguez D, Zhou X, Simmons R, Bethel CR, Hujer AM, Helfand MS et al. Tazobactam inactivation of SHV-1 and the inhibitor-resistant ser130 $\rightarrow$ Gly SHV-1 betalactamase. J Biol Chem 2004; 279: 19494-501.

14. Yazdi M, Nazemi A, Nargesi M, Khatami nejad M, Sharifi S, Kuchaksaraie M. [Prevalence of betalactamas resistance genes SHV/CTX-M/TEM in Eschrichia coli isolated from urinary tract infection in Tehran]. J Lab Sci 2010; 4:22-8. (Persian)

15.Masjedianjazi F, Valahi F, Talebi A, Rastegar lari A. [Mulecular investigation in extended spectrum betalactamase resistance in Eschrichia coli and Klebsiella Pneumoniae]. Iran Med Microbiol J 2007; 1:27-34. (Persian)

16. Yazdi M, Nazemi, Mirinargasi, Jafarpour, Sharifi SH . Genotypic versus phenotypic methods to detect extended-spectrum beta-lactamases in uropathogenic Escherichia coli. Ann Biolo Res 2012; 3:2454-8.

17. Moosavian M, Deiham B. Distribution of TEM, SHV and CTX-M genes among ESBLproducing Enterobacteriaceae isolates in Iran. Afr J Microbiol Res 2012; 6:5433-9

18. Miraalami Gh, Parviz M, Khalajzadeh S. Evaluation of antibiotic resistance in extendedspectrum betalactamase genes in the E. coli isolates of urinary infections. J Babol Uni Med 2015; 17:19-26. 
19.Farid S, Peeridogaheh H, Ghiami Rad M. [Prevalence of SHV-1 Type extended- spectrum $\beta$ lactamases in Enterobacteriaceae isolated from urinary samples in Ardabil Iran]. J Ardabil Uni Med Sci 2015; 15: 311- 19. (Persian)

20.Khosravi AD, Hoveizavi H, Mehdinejad M. Prevalence of Klebsiella pneumonia encoding genes for CTX-M-1, TEM-1 AND SHV-1 extended-spectrum beta lactmases enzymes in clinical specimens. Jundishapur J Microbiol 2013; 6:765-85. 


\title{
The Prevalence of SHV and SHV-1 Type of Extended-Spectrum- Betalactamase Genes in Escherichia coli Strains Isolated from Urine Samples of Patients Referring to Health Centers of Sanandaj
}

\author{
Zonouri $S^{1 *}$ Davari $K^{1}$, Mirzaie $S^{2}$
}

(Received: January 23, 2016

Accepted: February 27, 2016)

\begin{abstract}
Introduction: Today, emergence of extended spectrum betalactamase(ESBL) producing organisms are one of the health problems. Extended spectrum betalactamases are enzymes which cause the resistance to betalactam antibiotics. The aim of this study was to determine the antibiotic resistance pattern and prevalence of SHV and SHV-1 genes in ESBL producing Escherichia coli isolated from urinary tract infection in Sanandaj.
\end{abstract}

Materials \& methods: 150 isolated Escherichia coli from 406 urinary samples from patients referring to health center of Sanandaj were collected. All Eschrichia coli samples were identified by conventional biochemical tests. Antibiotic susceptibility testing was performed by disk diffusion method. Combined disk was also utilized as a confirmatory test, and results were compared with CLSI standards. The ESBL positive isolates were investigated by PCR for detecting SHV and SHV-1 genes.
Findings: From total of 150 Eschrichia coli isolates, resistance to ceftriaxone, pipracillin, gentamycin, amikacin, imipenem, ciprofloxacin, carbenicillin, cefepime, ceftazidime and cefotaxime were $29 \%, 58.5 \%, \quad 4.66 \%, \quad 10 \%, 33.25 \%$, $34.66 \%, 26 \%, 22 \%, 26 \%$ and $28.66 \%$ respectively. 43 isolates were ESBL positive and among them 34 isolates (79.6\%) contained SHV and 32 isolates (74.41\%) had SHV-1 gene.

Discussion \& conclusions: According to the results, the pravalence of antibiotic resistant strains and also ESBL producing strains in Sanandaj is high and finding ways to prevent the spread of these stains is important.

Keywords: Escherichia coli, Extended Spectrum Beta Lactamase, SHV, SHV-1

\footnotetext{
1. Dept of Microbiology, Faculty of Sience,Sanandaj Branch, Islamic Azad University, Sanandaj, Iran

2. Dept of Biochemistry Facultyof Sience, Sanandaj Branch, Islamic Azad University, Sanandaj, Iran

* Correspondin author Email: Sheidazonoori@gmail.com
} 